\title{
FAMÍLIAS DE COLEOPTERA CAPTURADAS COM ARMADILHA MALAISE EM OITO LOCALIDADES DO ESTADO DO PARANÁ, BRASIL. DIVERSIDADES ALFA E BETA
}

\author{
Renato C.Marinoni ${ }^{2}$ \\ Renato R.C. Dutra ${ }^{3}$
}

\begin{abstract}
FAMILIES OF COLEOPTERA CAPTURED WITH MALAISE TRAP IN EIGHT SITES of Parana State, Brazil. Alpita and Beta Diversities. Eight geographical areas, considered as representative of the different natural environments still existing in the state of Paraná, in Southern Brazil, were selected for the collection of insects. This data is part of the "Survey of the Entomological Fauna in Paraná State" (henceforth PROFAUPAR). These areas were continually sampled using a Malaise trap (TOWNES' 1972 model) throughout a single year (52 weeks) from August, 1986, until July 1987. The Coleoptera obtained has been sorted at family level and analyzed. The highest family variety and abundance were observed at Jundiai do Sul and Ponta Grossa, and the greatest eveness at Jundiai do Sul and Telêmaco Borba. A study on phytophagous/non phytophagous families relations made possible a first approach about the vegetation condition in the sites. The following methods were used to analyse the data: Ecological Indices (Alpha Diversity) and Clustering and Ordination Analysis (Beta Diversity).

KEY WORDS. Coleoptera, Alpha Diversity, Beta Diversity, Trophic relations, Paraná
\end{abstract}

Anteriormente, em MARINONI \& DUTRA (1993), foram definidos os propósitos do Projeto "Levantamento da Fauna Entomológica no Estado do Paraná" (PROFAUPAR). Naquela oportunidade, indicava-se que um segundo tratamento dos dados faunísticos seria a análise de grupos de insetos a níveis taxonômicos inferiores a Ordem, com a análise dos dados ao nível da diversidade alfa (diferentes índices ecológicos) e da diversidade beta (análise de agrupamento).

Os estudos decorrentes das coletas realizadas pelo PROFAUPAR têm como objetivo principal uma avaliação das condições das áreas ainda preservadas no Paraná, como mantenedoras de uma diversidade faunistica, capaz de servir como estoque para repovoamentos ou sustentação das condições ambientais dentro da própria área (MARINONI \& DUTRA 1993).

1) Contribuição número 958 do Departamento de Zoologia, Universidade Federal do Paraná.

2) Departamento de Zoologia, Universidade Federal do Paraná. Caixa Postal 19020, 81531-990 Curitiba, Paraná, Brasil. Bolsista do CNPq.

3) Escola Técnica, Universidade Federal do Paraná. 81520-260 Curitiba, Paraná, Brasil. 
No momento, os trabalhos que estão sendo realizados, utilizando principalmente algumas famílias de Lepidoptera (Ctenuchidae, Saturniidae e Sphingidae), Coleoptera (Cerambycidae e Elateridae) e Hymenoptera (Ichneumonidae), têm como objetivo avaliar a adequação destes grupos para a mensuração da diversidade nas áreas estudadas, além de testar vários índices que são indicados na literatura para esta finalidade. $\mathrm{O}$ uso de diferentes índices reflete a dificuldade de estabelecer comparações com apoio em um único índice, tendo em vista a utilização de diferentes parâmetros no cálculo de cada um deles, levando a enfatizar, para mais ou menos, o número de espécies ou o número de indivíduos. O que se pretende é definir quais os grupos de insetos que, quando analisados em conjunto, nos permitam avaliar a diversidade faunística destas áreas que estão sendo estudadas, já que a quantificação absoluta da biodiversidade não é operacionalmente factível.

Aqui são utilizados os dados relativos às famílias de Coleoptera (Tab. I), cujos indivíduos foram capturados com armadilha Malaise durante o PROFAUPAR, e que foram anteriormente estudados por DUTRA \& MIYAZAKI (1994) ao analisarem a ocorrência e a quantidade de indivíduos por família, classificando-as quanto à constância e dominância.

A análise de diversidade ao nível de família taxonômica é raramente considerada, mas sua aplicação é admitida por Pielou (1975) e MagurRan (1988); e HUTCHESON (1990) utilizou esta categoria taxonômica para obter interessantes resultados em estudos de comunidades de Coleoptera associadas à sucessão vegetal.

Além disso, os Coleoptera se constituem, em termos de biomassa de Arthropoda, como um importante componente do Ecossistema Floresta Tropical (PENNY \& ARIAS 1982). Muitos pesquisadores sugerem que os Coleoptera, os quais utilizam muitos nichos tróficos e compreendem não menos que $40 \%$ de todas as espécies de Insecta e $30 \%$ de todas as espécies animais (LAWRENCE \& BRITTON 1991), são geralmente representativos da riqueza da entomofauna (HUTCHESON 1990).

Assim, o presente trabalho, teve os seguintes objetivos: 1) estabelecer as diversidades alfa e beta das oito localidades amostradas, com base em famílias de Coleoptera; 2) comparar os resultados obtidos a partir de cada um dos índices utilizados na mensuração das condições ambientais; 3) relacionar a estrutura da comunidade de Coleoptera às condições florísticas dos locais de captura; 4) contribuir com novos elementos para uma futura avaliação envolvendo todos os dados levantados através do PROFAUPAR.

\section{MATERIAL E MÉTODOS}

\section{Coleta e identificação do material}

Em agosto de 1986, com o início do PROFAUPAR, oito pontos de coleta foram estabelecidos: um na área litorânea (Antonina); um na Serra do Mar (São José dos Pinhais); um no Primeiro planalto paranaense (Colombo); três no Segundo planalto paranaense (Ponta Grossa, Jundiaí do Sul e Telêmaco Borba); dois no Terceiro planalto paranaense (Guarapuava e Fênix). Nestes pontos de coleta, cujas localiza- 
ções, com situações climáticas e florísticas, podem ser encontradas em MARINONI $\&$ DUTRA (1993), foram instaladas armadilhas do tipo Malaise (TOWNES 1972), por um período de 52 semanas (agosto/1986 - julho/1987).

Os critérios utilizados para a definição dos locais e fixação das armadilhas também podem ser encontrados em MARINONI \& DUTRA (1993).

O material capturado foi triado a nível de ordem, sendo que os Coleoptera foram identificados a nível de família, segundo a classificação de CROWSON (1967), com modificações de LAWRENCE (1982). A manutenção de Platypodidae e de Scolytidae como famílias de Coleoptera, que era a condição anterior à classificação dos autores acima, visou apenas facilitar a explicação de certas relações entre grupos tróficos observadas na análise de estrutura de comunidade.

\section{Análise dos dados}

\section{Diversidade Alfa}

Além do número de famílias e indivíduos, por localidade, a diversidade alfa foi obtida e analisada a partir de índices de diversidade e de dominância/uniformidade (MAGURRAN 1988; MARINONI \& DUTRA 1996). Os de diversidade foram: 1) de Brillouin (HB); 2) de Shannon (H'); 3) de Margalef (M). Os índices de dominância/uniformidade utilizados foram: 1) de Shannon (H’E); de Berger \& Parker (UBP); de Simpson (1/D).

\section{Diversidade Beta}

A partir da tabela I, onde estão os totais de indivíduos por família em cada um dos oito pontos amostrados, foram geradas duas matrizes de dados. Uma com valores de captura média de cada família (número de indivíduos/número de amostras por localidade) (composição de famílias); e outra, com estes valores ordenados por nível de dominância de família em cada local (estrutura de comunidade).

Com base nestas matrizes, procurou-se estabelecer a relação de semelhança entre os pontos amostrados, utilizando-se as Análise de Agrupamento e Análise por Coordenadas Principais (SNEATH \& SOKAL 1973; BRAY \& CURTIS 1957); o coeficiente de similaridade e o método de agrupamento utilizados estão indicados com a apresentação dos resultados; os cálculos e gráficos foram feitos através do programa NTSYS-pc (versão 1.80) (ROHLF 1994).

\section{Estrutura de comunidade e niveis tróficos}

A partir da matriz de dados de captura média ordenados por dominância (ver acima) e da identificação das famílias dominantes em níveis tróficos, foram analisadas as relações entre duas guildas - dos fitófagos e dos não-fitófagos (detalhes do método estão em Resultados e Discussão).

\section{Material testemunha}

Encontra-se depositado na Coleção de Entomologia Pe. Jesus Santiago Moure, no Departamento de Zoologia da Universidade Federal do Paraná. 


\section{RESULTADOS E DISCUSSÃO}

\section{Diversidade AlFA (Tabs I e II)}

\section{Número de famílias representadas e de indivíduos capturados por localidade}

O número total de famílias em cada uma das localidade, em ordem decrescente foi: Jundiaí do Sul/Ponta Grossa (ambas com 64 famílias), Fênix (57), Telêmaco Borba (55), Colombo (53), Guarapuava (49), Antonina (48) e São José dos Pinhais (47).

Quando considerado o número de exemplares, a seqüência das localidades, em ordem decrescente, foi: Jundiaí do Sul, Ponta Grossa, Telêmaco Borba, Fênix, Antonina, Guarapuava, Colombo e São José dos Pinhais, havendo um relativa correspondência entre o número de famílias e o número de indivíduos. Se comparada à seqüência em ordem decrescente do total de Insecta, por localidade (MARINONI \& DUTRA 1993), as seis primeiras localidades têm o mesmo posicionamento, havendo troca de posição entre as duas localidades com menor número de indivíduos: São José dos Pinhais e Colombo

Destacamos a condição de Colombo que está representada por mais famílias que Guarapuava, Antonina e São José dos Pinhais. O fato de ser a localidade com o menor número de exemplares de Insecta capturados, e a segunda localidade com o menor número de exemplares de Coleoptera, além de ser a que se apresenta mais destruída, segundo as observações de Hatschbach (in MARINONI \& DUTRA 1993), poderia fazer supor que seria aquela com o menor número de famílias capturadas.

\section{Índices de diversidade (Tab. II)}

De Brillouin (HB). O cálculo deste índice, que se aplica aos dados que representam coleções, apresentou valores de diversidade que indicam, em ordem decrescente, a seguinte seqüência das localidades: Jundiaí do Sul, Telêmaco Borba, Guarapuava, Fênix, Ponta Grossa, Colombo, Antonina e São José dos Pinhais.

De Shannon (H'). A seqüência das localidades, na ordem decrescente dos valores obtidos, foi: Jundiaí do Sul, Telêmaco Borba, Guarapuava, Fênix, Colombo, Ponta Grossa, Antonina e São José dos Pinhais.

As únicas localidades que alteram suas posições quando comparados os dois índices são as de Ponta Grossa e Colombo. Esta alternância apoiada em diferenças mínimas de valores entre ambas.

De Margalef (M). Os resultados deste índice indicaram a seguinte ordem das localidades, por valores decrescentes: Ponta Grossa, Fênix, Colombo, Jundiaí do Sul, Telêmaco Borba, Guarapuava, São José dos Pinhais e Antonina.

\section{Discussão}

Os resultados apresentados pelos índices de Brillouin e Shannon indicam condições de diversidade praticamente iguais para as oito localidades, se comparados os valores que vão da maior à menor diversidade. Alternaram posições apenas as localidades de Ponta Grossa e Colombo. Os valores do índice de Shannon sendo sempre superiores por razões puramente matemáticas (LLOYD et al. 1968). Os 
Tabela I. Total de indivíduos por família de Coleoptera, capturados com armadilha Malaise em oito localidades do Estado do Paraná, no período de agosto de 1986 a julho de 1987. (AN) Antonina, (CO) Colombo, (FE) Fênix, (GU) Guarapuava, (JS) Jundiai do Sul, (PG) Ponta Grossa, (SJ) São José dos Pinhais, (TB) Telêmaco Borba.

\begin{tabular}{|c|c|c|c|c|c|c|c|c|}
\hline Familias & AN & SJ & $\mathrm{CO}$ & PG & GU & FE & JS & TB \\
\hline Aderidae & 3 & 0 & 0 & 27 & 0 & 2 & 189 & 2 \\
\hline Alleculidae & 2 & 9 & 10 & 44 & 7 & 1 & 48 & 0 \\
\hline Anisotomidae & 1 & 0 & 0 & 1 & 0 & 0 & 11 & 4 \\
\hline Anobiidae & 4 & 1 & 4 & 53 & 1 & 28 & 85 & 16 \\
\hline Anthicidae & 0 & 0 & 0 & 4 & 2 & 0 & 1 & 3 \\
\hline Anthribidae & 23 & 7 & 13 & 31 & 12 & 40 & 26 & 11 \\
\hline Biphyllidae & 0 & 7 & 8 & 0 & 2 & 1 & 0 & 1 \\
\hline Bostrychidae & 0 & 0 & 0 & 1 & 0 & 0 & 16 & 1 \\
\hline Brenthidae & 0 & 0 & 0 & 0 & 2 & 3 & 4 & 0 \\
\hline Bruchidae & 1 & 0 & 2 & 4 & 2 & 0 & 27 & 0 \\
\hline Buprestidae & 4 & 7 & 3 & 5 & 0 & 13 & 12 & 31 \\
\hline Cantharidae & 6 & 67 & 15 & 113 & 4 & 0 & 55 & 21 \\
\hline Carabidae & 21 & 14 & 4 & 41 & 9 & 15 & 171 & 20 \\
\hline Cerambycidae & 64 & 20 & 66 & 255 & 108 & 314 & 367 & 78 \\
\hline Chelonariidae & 1 & 3 & 2 & 38 & 19 & 11 & 38 & 3 \\
\hline Chrysomelidae & 472 & 303 & 211 & 1203 & 143 & 151 & 801 & 243 \\
\hline Ciidae & 0 & 0 & 0 & 1 & 0 & 0 & 0 & 0 \\
\hline Cicindelidae & 8 & 0 & 5 & 0 & 0 & 1 & 0 & 27 \\
\hline Cleridae & 81 & 9 & 11 & 123 & 24 & 34 & 70 & 44 \\
\hline Coccinellidae & 69 & 15 & 19 & 28 & 12 & 24 & 85 & 96 \\
\hline Colydiidae & 0 & 0 & 0 & 0 & 1 & 0 & 0 & 0 \\
\hline Corylophidae & 1 & 1 & 1 & 15 & 0 & 6 & 59 & 1 \\
\hline Cryptophagidae & 1 & 1 & 3 & 2 & 11 & 26 & 12 & 5 \\
\hline Cucujidae & 1 & 6 & 15 & 14 & 10 & 61 & 240 & 5 \\
\hline Curculionidae & 175 & 120 & 319 & 423 & 236 & 264 & 589 & 314 \\
\hline Dascillidae & 0 & 1 & 0 & 0 & 0 & 0 & 0 & 0 \\
\hline Dermestidae & 0 & 1 & 0 & 1 & 0 & 3 & 1 & 4 \\
\hline Dryopidae & 0 & 1 & 0 & 0 & 0 & 0 & 1 & 1 \\
\hline Dytiscidae & 2 & 0 & 0 & 5 & 0 & 1 & 2 & 0 \\
\hline Elateridae & 24 & 26 & 52 & 340 & 56 & 159 & 564 & 218 \\
\hline Elminthidae & 7 & 1 & 0 & 1 & 0 & 0 & 2 & 0 \\
\hline Endomychidae & 0 & 1 & 1 & 4 & 2 & 3 & 17 & 0 \\
\hline Erotylidae & 20 & 5 & 13 & 31 & 12 & 21 & 79 & 24 \\
\hline Eucnemidae & 21 & 0 & 8 & 25 & 4 & 6 & 38 & 11 \\
\hline Helotidae & 18 & 45 & 5 & 19 & 0 & 0 & 16 & 3 \\
\hline Histeridae & 0 & 0 & 1 & 1 & 0 & 0 & 2 & 5 \\
\hline Hydrophilidae & 14 & 26 & 1 & 8 & 0 & 0 & 13 & 1 \\
\hline Lagriidae & 0 & 3 & 1 & 13 & 10 & 4 & 22 & 3 \\
\hline Lampyridae & 36 & 32 & 36 & 17 & 37 & 2 & 84 & 68 \\
\hline Languriidae & 1 & 0 & 0 & 3 & 3 & 0 & 2 & 15 \\
\hline Lathridiidae & 1 & 0 & 1 & 12 & 0 & 6 & 37 & 22 \\
\hline Limnichidae & 0 & 0 & 0 & 1 & 0 & 0 & 0 & 0 \\
\hline Lissomidae & 0 & 0 & 0 & 0 & 0 & 1 & 0 & 1 \\
\hline Lucanidae & 0 & 2 & 2 & 1 & 2 & 0 & 0 & 0 \\
\hline
\end{tabular}


Tabela I. Continuação.

\begin{tabular}{|c|c|c|c|c|c|c|c|c|}
\hline Familias & AN & SJ & $\mathrm{CO}$ & PG & GU & FE & JS & TB \\
\hline Lycidae & 11 & 2 & 3 & 28 & 20 & 22 & 87 & 41 \\
\hline Lyctidae & 0 & 0 & 0 & 0 & 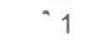 & 1 & 1 & 1 \\
\hline Lymexylidae & 0 & 0 & 0 & 0 & 1 & 1 & 1 & 0 \\
\hline Melandryidae & 5 & 0 & 4 & 33 & 10 & 5 & 40 & 2 \\
\hline Meloidae & 6 & 1 & 0 & 0 & 0 & 1 & 4 & 3 \\
\hline Melyridae & 0 & 0 & 4 & 36 & 2 & 3 & 11 & 1 \\
\hline Monommidae & 0 & 0 & 4 & 1 & 0 & 0 & 1 & 0 \\
\hline Mordellidae & 133 & 26 & 78 & 383 & 75 & 193 & 269 & 245 \\
\hline Mycetophagidae & 13 & 24 & 29 & 54 & 10 & 13 & 28 & 11 \\
\hline Mycteridae & 0 & 0 & 2 & 7 & 1 & 8 & 2 & 0 \\
\hline Nilionidae & 0 & 0 & 0 & 0 & 0 & 1 & 0 & 2 \\
\hline Nitidulidae & 27 & 8 & 46 & 142 & 41 & 44 & 103 & 105 \\
\hline Noteridae & 0 & 0 & 0 & 1 & 0 & 0 & 0 & 0 \\
\hline Oedemeridae & 7 & 9 & 7 & 4 & 3 & 0 & 6 & 6 \\
\hline Ostomatidae & 0 & 0 & 0 & 2 & 0 & 2 & 0 & 0 \\
\hline Pedilidae & 0 & 1 & 0 & 4 & 0 & 24 & 0 & 4 \\
\hline Phalacridae & 20 & 4 & 2 & 105 & 5 & 37 & 229 & 70 \\
\hline Phengodidae & 29 & 29 & 19 & 3 & 15 & 65 & 58 & 67 \\
\hline Plastoceridae & 0 & 0 & 0 & 0 & 0 & 1 & 0 & 0 \\
\hline Platypodidae & 29 & 1 & 8 & 5 & 1 & 4 & 7 & 0 \\
\hline Pselaphidae & 12 & 3 & 1 & 8 & 0 & 1 & 17 & 2 \\
\hline Ptiliidae & 5 & 0 & 0 & 0 & 2 & 0 & 1 & 0 \\
\hline Ptilodactylidae & 23 & 69 & 38 & 45 & 96 & 10 & 63 & 63 \\
\hline Ptinidae & 0 & 0 & 0 & 6 & 0 & 5 & 20 & 0 \\
\hline Rhipiceridae & 0 & 0 & 1 & 0 & 0 & 0 & 0 & 0 \\
\hline Rhipiphoridae & 0 & 1 & 1 & 0 & 3 & 0 & 0 & 2 \\
\hline Rhizophagidae & 0 & 0 & 10 & 9 & 3 & 1 & 13 & 0 \\
\hline Scaphidiidae & 1 & 1 & 2 & 19 & 2 & 3 & 157 & 11 \\
\hline Scarabaeidae & 8 & 22 & 12 & 47 & 57 & 2 & 134 & 12 \\
\hline Scolytidae & 72 & 24 & 17 & 27 & 38 & 12 & 88 & 145 \\
\hline Scydmaenidae & 4 & 1 & 1 & 5 & 0 & 1 & 11 & 0 \\
\hline Staphylinidae & 230 & 145 & 65 & 348 & 92 & 176 & 921 & 232 \\
\hline Tenebrionidae & 6 & 2 & 6 & 19 & 14 & 29 & 69 & 3 \\
\hline Trixagidae & 0 & 0 & 0 & 36 & 0 & 5 & 19 & 2 \\
\hline Trogositidae & 0 & 0 & 1 & 2 & 1 & 2 & 6 & 0 \\
\hline Total de indivíduos & 1723 & 1107 & 1193 & 4287 & 1224 & 1873 & 6152 & 2332 \\
\hline Total de familias & 48 & 47 & 53 & 64 & 49 & 57 & 64 & 55 \\
\hline Total de amostras & 50 & 51 & 51 & 51 & 52 & 52 & 52 & 52 \\
\hline
\end{tabular}

valores indicados pelo índice de Margalef, independente de grandeza, diferem muito dos dois primeiros índices quanto à condição de maior ou menor diversidade de cada uma das localidades. $\mathrm{O}$ índice de Margalef minimiza a expressão do número de indivíduos capturados $(\mathrm{N})$, resultando que Jundiai do Sul, tendo o mesmo número de táxons que Ponta Grossa apresenta um índice menor que o desta localidade, que apresenta um $\mathrm{N}$ cerca de $1 / 3$ menor. 
Os resultados apresentados pelos índices não trazem nenhum elemento maior que aqueles fornecidos pelos valores de $\mathrm{S}$ (variedade de táxons) e $\mathrm{N}$ (número de indivíduos capturados), para apoiar uma interpretação biológica sobre a diversidade das localidades, como já observado por MAC ARTHUR (1965); WILLIAMSON (1973); POOLE (1974) e PEET (1974).

Desta forma, vemos que os valores simples, de variedade de táxons (S) e do número de indivíduos capturados $(\mathrm{N})$, apontam para uma maior variedade $(\mathrm{S}) \mathrm{em}$ Jundiaí do Sul e Ponta Grossa, onde também se observam os maiores números de indivíduos capturados (N). A simples interpretação destes dados nos indicam estes locais, juntamente com Fênix e Telêmaco Borba, como os que detêm as melhores condições de diversidade, e as localidades de São José dos Pinhais e Antonina, as piores.

\section{Índices de dominância/uniformidade (Tab. II).}

De Shannon (H'E). A sequiência, na ordem decrescente dos valores obtidos, foi: Jundiaí do Sul/Guarapuava (com valores praticamente iguais), Telêmaco Borba, Fênix, São José dos Pinhais/Antonina (com valores praticamente iguais), Colombo e Ponta Grossa.

De Berger \& Parker (UBP). Este índice, originalmente uma medida de dominância, mas que na sua forma inversa adquire características de uniformidade, apresentou a seguinte seqüência em ordem decrescente dos valores obtidos: Telêmaco Borba, Jundiaí do Sul, Fênix, Guarapuava, Colombo, Antonina/São José dos Pinhais (com valores iguais) e Ponta Grossa.

Se comparada à seqüência obtida para o $H^{\prime} E$, as quatro primeiras localidades são as mesmas, apesar de apresentarem posições relativas distintas.

De Simpson (1/D). Do mesmo modo que o índice de Berger \& Parker, o índice de Simpson é originalmente uma medida de dominância, aqui utilizada na sua forma inversa e anotado como um índice de uniformidade. A seqüência, na ordem decrescente dos valores obtidos, foi: Jundiaí do Sul, Telêmaco Borba, Guarapuava, Fênix, Ponta Grossa, Antonina/São José dos Pinhais (com valores iguais) e Colombo.

\section{Discussão}

Uma primeira análise dos valores obtidos através dos dois últimos índices (UBP e 1/D) indica um resultado assemelhado no que tange à dominância/uniformidade entre as famílias de Coleoptera, nas oito localidades. Quatro delas (Telêmaco Borba, Jundiaí do Sul, Guarapuava e Fênix) com valores de uniformidade destacadamente superiores aos das quatro outras localidades.

O índice de Simpson (1/D) é fortemente afetado pelos valores dos três táxons mais abundantes (WHITTAKER 1972); o índice de Shannon (H'E) é muito influenciado pela somatória dos cinco táxons mais abundantes; enquanto o índice de Berger \& Parker (UBP) tem seu cálculo apoiado no número de índividuos da família mais abundante. Assim, o ordenamento das localidades, baseado no valor percentual da família mais abundante, estabelece a mesma ordem de seqüência das localidades que o índice de Berger \& Parker; da mesma forma que o cálculo simples da soma da freqüência percentual das três e cinco famílias mais abundantes, por localidade, mostraram valores que resultaram em seqüências de localidades quase iguais 
àquelas definidas pelos índices de Simpson e Shannon, respectivamente. Os dois primeiros índices, UBP e 1/D, ordenadas as localidades, mostram resultados assemelhados, diferindo muito mais do índice de uniformidade de Shannon (H'E), que dos índices de diversidade de Brillouin (HB) e do próprio Shannon (H').

Tabela II. Diversidade e Uniformidade/Dominância das familias de Coleoptera. (S) Número de famílias; $(\mathrm{N})$ número de individuos; (HB) indice de diversidade de Brillouin; ( $\mathrm{H}^{\prime}$ ) indice de diversidade de Shannon; (M) indice de diversidade de Margalef; $\left(H^{\prime} E\right)$ indice de uniformidade de Shannon; (UBP) forma inversa do indice de dominância de Berger \& Parker; (1/D) forma inversa do índice de dominância de Simpson.

\begin{tabular}{lcccccccc}
\hline \multicolumn{1}{c}{ Localidades } & $\mathrm{S}$ & $\mathrm{N}$ & $\mathrm{HB}$ & $\mathrm{H}^{\prime}$ & $\mathrm{M}$ & $\mathrm{H}^{\prime} \mathrm{E}$ & $1 / \mathrm{D}$ & UBP \\
\hline Antonina & 48 & 1723 & 1,164 & 2,746 & 6,307 & 0,709 & 8,475 & 3,650 \\
São José dos Pinhais & 47 & 1107 & 1,148 & 2,732 & 6,563 & 0,710 & 8,475 & 3,650 \\
Colombo & 53 & 1193 & 1,168 & 2,785 & 7,340 & 0,702 & 8,333 & 3,745 \\
Ponta Grossa & 64 & 4287 & 1,198 & 2,783 & 7,533 & 0,660 & 8,547 & 3,559 \\
Guarapuava & 49 & 1224 & 1,239 & 2,934 & 6,751 & 0,754 & 12,048 & 5,181 \\
Fênix & 57 & 1873 & 1,228 & 2,888 & 7,432 & 0,714 & 11,628 & 5,952 \\
Jundiai do Sul & 64 & 6152 & 1,347 & 3,138 & 7,221 & 0,755 & 14,286 & 6,667 \\
Telêmaco Borba & 55 & 2332 & 1,275 & 2,972 & 6,964 & 0,742 & 13,889 & 7,407 \\
\hline
\end{tabular}

\section{Considerações}

Como os índices de diversidade incorporam elementos de abundância dos vários táxons envolvidos, parece mais ajustado interpretar-se a diversidade com base apenas em dados de $\mathrm{S}$ (número de espécies) e $\mathrm{N}$ (número de indivíduos), e utilizar índices apenas para as análises de dominância/uniformidade.

Deste modo, Jundiaí do Sul e Ponta Grossa apresentam os maiores valores de diversidade de Coleoptera, e Antonina e São José dos Pinhais, os menores. Quanto à uniformidade, os maiores valores são os apresentados por Jundiaí do Sul e Telêmaco Borba, e os menores os observados em Ponta Grossa, Antonina, São José dos Pinhais e Colombo, todas estas localidades quase num mesmo nível.

\section{Análise das famílias de Coleoptera a partir de níveis tróficos}

\section{Classificação em guildas}

Os besouros constituem o táxon que apresenta o maior número de espécies de todo o reino animal, sendo encontrados nos mais diversos nichos tróficos. O ordenamento das famílias em ordem decrescente do número de indivíduos, por localidade, permitiu visualizar uma dominância das famílias de hábitos fitófagos. Este fato levou-nos a classificar as famílias em duas guildas: fitófagos e não-fitófagos. Esta divisão simples, em apenas dois grupos, decorre da extrema dificuldade em estabelecer os hábitos alimentares da maioria das famílias de Coleoptera. Outra dificuldade é a existência, dentro de uma mesma família, de grupos de espécies com diferentes hábitos alimentares ou, ainda, com as fases larvais tendo um nicho trófico diverso daquele dos adultos (LIMA 1952-1956; LAWRENCE \& BRITTON 1991; CROWSON 1981; COSTA et al. 1988). As famílias arroladas a seguir foram as que se apresentaram como dominantes ao nível de $60 \%$ do total de indivíduos de cada localidade (ver adiante). 
Fitófagos. Incluímos entre os besouros fitófagos aqueles que têm, principalmente em sua vida vegetativa, uma relação estreita com os vegetais vivos ou, algumas vezes, recém-mortos pela ação dos próprios indivíduos da espécie. Apesar dos poucos conhecimentos, é possível admitir que parte das espécies que vivem no lenho têm como alimento espécies de fungos, que se desenvolvem nas galerias, por uma infestação conduzida, ou não, pelo besouro.

Curculionidae. Os dados biológicos conhecidos desta família indicam que há espécies, principalmente nas fases larvais, alimentando-se em todas as partes vivas da estrutura vegetal: folhas, flores, frutos, sementes, caules (lenhos), raízes. Os indivíduos da família Scolytidae (Scolytinae segundo CrowsON 1967) foram incluídos na guilda dos não-fitófagos, devido ao hábito micófago das larvas. Esta posição é discutível, já que o alimento inicial das larvas, quando formam as galerias, onde posteriormente se desenvolve o fungo, parece ser o lenho.

Chrysomelidae. Grupo com hábitos alimentares semelhantes aos dos Curculionidae, mas com forte predominância de espécies filófagas. Algumas espécies são encontradas no folhiço.

Cerambycidae. Espécies com larvas de hábitos xilófagos. Raras são espermófagas. Fêmeas de alguns gêneros cortam o caule de plantas vivas onde fazem a postura dos ovos. A grande maioria faz a postura em troncos e galhos de plantas recém-mortas por ação de diferentes agentes. Relativamente poucas espécies (subfamílias Prioninae, Parandrinae) têm as larvas se desenvolvendo em madeira em estado mais avançado de decomposição. HUTCHESON (1990) incluiu os Cerambycidae na guilda dos coleópteros detritívoros. A inclusão dos Cerambycidae como membro da guilda dos fitófagos nos parece mais adequada, considerando que a estrutura lignificada dos vegetais tem relativamente poucas alterações no seu conteúdo alimentar logo após o cessamento da atividade metabólica, que é a fase em que a grande maioria das espécies da família apresenta a sua atividade alimentar, e a sua estrutura não foi alterada pela ação de agentes decompositores (principalmente fungos e bactérias).

Não-fitófagos. Dentro desta guilda foram incluídas as demais famílias, inclusive as micófagas e as que não se caracterizam como essencialmente fitófagas. Algumas delas apresentam grupos de espécies que se alimentam de vegetais, mas os escassos conhecimentos sobre o comportamento das espécies não permitem que se as reconheçam como maioria. Outras são identificadas pelo hábito fitófago de formas adultas, as quais foram aqui consideradas como formas não vegetativas, e de importância menor que as larvas no processo da cadeia alimentar.

Staphylinidae. Família numerosa com uma gama muito variada de hábitos alimentares, seja na forma adulta ou larval. Encontrados em vegetais em decomposição (folhiço), tendo hábitos saprófagos e coprófagos. Algumas espécies são predadoras, outras parasitas. Há citações da existência de espécies alimentando-se de fungos/musgos.

Mordellidae. Família que surpreendeu pelo alto número de indivíduos capturados se considerada a existência no Brasil de apenas cerca de 8 gêneros e 125 espécies (CosTA et al. 1988). Há dificuldades para a correta classificação trófica desta família. CosTA et al. (1988) não fizeram referências expressas aos hábitos alimentares, mas indicam larvas desta família vivendo em galerias escavadas em 
madeira apodrecida ou no caule de plantas herbáceas. LIMA (1955) citando o hábito cecidófago para umas e micófago para outras larvas, escreveu faltar confirmação para o possível hábito predador das larvas. LAWRENCE \& BRITTON (1991), além destes, indicam o hábito predador ou parasita da larva. E, CROwson (1981), não fazendo referência explicita à condição de predadora da larva, anota que há observações de larvas de Mordellidae predando larvas de Lepidoptera e Diptera quando as encontram em um caule.

Elateridae. As larvas desta família podem ser predadoras, fitófagas, saprófagas, estas vivendo no folhiço. Apesar de HUTCHESON (1990) ter incluído esta família entre os comedores de plantas vivas, a classificamos como não-fitófaga, principalmente pela condição predadora e saprófaga de grande parte das espécies.

Ptilodactylidae. As larvas vivem próximas a ambientes aquáticos em madeiras em decomposição, tendo hábitos saprófagos. Os adultos são observados em vegetação próxima à água, sendo considerados florícolas, principalmente polinívoros. Esta família não está arrolada entre aquelas indicadas por HUTCHESON (1990).

Scolytidae. Ver acima em Curculionidae.

Cucujidae. Espécies desta família são consideradas predadoras, com algumas atacando grãos e frutos secos armazenados.

Nitidulidae. Família de hábitos alimentares bem diversificados. Podem ser predadores, necrófagos, saprófagos, fitófagos (florífagos) (CosTA et al. 1988). Mesmo que, no presente estudo, a representatividade de Nitidulidae seja muito pequena, optamos pela sua classificação como não-fitófago, diferentemente de HUTCHESON (1990).

Cleridae. As larvas são predadoras, principalmente de besouros xilófagos. Algumas espécies alimentam-se de matéria animal ou vegetal mortas.

Cantharidae. Larvas são primariamente predadoras.

\section{Resultados e Discussão}

Numa tentativa experimental, consideramos a presença do número de indivíduos das famílias dominantes em dois estudos; um envolvendo $50 \%$ do total de indivíduos de Coleoptera capturados em cada localidade e um outro com $60 \%$ do total.

A escolha para análise do estudo com $60 \%$ do total de indivíduos (Tab. III) foi decorrência:

a) da inclusão, nestes $60 \%$, de mais de $10 \%$ do total de famílias dentre as dominantes, em 6 das 8 localidades estudadas (7/64 famílias em Jundiaí do Sul; 7/55 em Telêmaco Borba; 6/49 em Guarapuava; 6/57 em Fênix; 5/48 em São José dos Pinhais; $5 / 48$ em Antonina); tendo apenas 2 localidades com menos de 10\% (4/53 em Colombo e 5/64 em Ponta Grossa).

b) do uso bastante comum dos índices de dominância de Berger \& Parker, que se apoia no valor do táxon mais abundante; de Simpson e Shannon, que são fortemente afetados pelos valores das três e cinco famílias mais abundantes, respectivamente, e, portanto, utilizando valores que se incorporam dentro dos $60 \%$ aqui arbitrados.

Ao nível de $60 \%$ do total de indivíduos capturados, os fitófagos dominam 
Tabela III. Famílias de Coleoptera dominantes incluídas em $60 \%$ do total de indivíduos capturados em cada uma das oito localidades, classificadas por guilda: (AN) Antonina, (CO) Colombo, (FE) Fênix, (GU) Guarapuava, (JS) Jundiaí do Sul, (PG) Ponta Grossa, (SJ) São José dos Pinhais, (TB) Telêmaco Borba.

\begin{tabular}{|c|c|c|c|c|c|c|c|c|}
\hline Familias & AN & SJ & $\mathrm{CO}$ & PG & GU & FE & JS & TB \\
\hline Total familias & 48 & 47 & 53 & 64 & 49 & 57 & 64 & 55 \\
\hline Total individuos & 1723 & 1107 & 1193 & 4287 & 1224 & 1873 & 6152 & 2332 \\
\hline $60 \%$ do total & 1034 & 664 & 716 & 2572 & 734 & 1124 & 3691 & 1399 \\
\hline \multicolumn{9}{|l|}{ FITÓFAGOS } \\
\hline Curculionidae & 175 & 120 & 319 & 423 & 236 & 264 & 589 & 314 \\
\hline Chrysomelidae & 472 & 303 & 211 & 1203 & 143 & $18 \mathrm{a}$ & 801 & 243 \\
\hline Cerambycidae & * & * & 66 & * & 108 & 314 & 367 & * \\
\hline $\begin{array}{l}\text { Totais } \\
\text { NÄO FITÓFAGOS }\end{array}$ & 647 & 423 & 596 & 1626 & 487 & 596 & 1757 & 557 \\
\hline Staphylinidae & 230 & 145 & $42 a$ & 348 & 92 & 176 & 921 & 232 \\
\hline Mordellidae & 133 & * & 78 & 383 & $59 a$ & 193 & 269 & 245 \\
\hline Elateridae & * & * & * & $215 a$ & $*$ & 159 & 564 & 218 \\
\hline Ptilodactylidae & * & 69 & * & * & 96 & * & * & * \\
\hline Scolytidae & * & * & * & * & * & * & * & 145 \\
\hline Cucujidae & * & * & * & * & * & * & $180 a$ & * \\
\hline Cleridae & $24 \mathrm{a}$ & * & * & * & * & * & * & * \\
\hline Nitidulidae & * & * & * & * & * & * & * & $2 a$ \\
\hline Cantharidae & * & $2 \mathrm{a}$ & * & * & * & * & * & $*$ \\
\hline Totais & 387 & 241 & 120 & 946 & 247 & 528 & 1934 & 842 \\
\hline Não fitófagos / fitófagos & 0,598 & 0,570 & 0,201 & 0,582 & 0,507 & 0,886 & 1,101 & 1,512 \\
\hline
\end{tabular}

*) valor não anotado por ser inferior aos que se incluiram entre os $60 \%$ do total de indivíduos pertencentes às famílias dominantes.

a) a familia de mais baixo número de individuos arrolada dentre as dominantes contribuiu, para o total da guilda a que pertence, com apenas o número de indivíduos suficiente para completar o total de $60 \%$ da localidade.

sobre os não-fitófagos, exceto em Jundiaí do Sul e Telêmaco Borba.

Dentre as famílias dominantes foram arroladas somente três famílias fitófagas, quando consideradas todas as localidades: Curculionidae, Chrysomelidae, Cerambycidae. Destas, somente as duas primeiras estiveram presentes nas oito localidades. Dentre as famílias não-fitófagas foram arroladas nove: Staphylinidae, Mordellidae, Elateridae, Ptilodactylidae, Scolytidae, Cucujidae, Nitidulidae, Cleridae e Cantharidae. Apenas a primeira apareceu entre as dominantes em todas as localidades, e as quatro últimas em apenas uma localidade cada.

Estabelecendo-se uma relação entre não-fitófagos (NF) e fitófagos (F) $(=\mathrm{NF} / \mathrm{F})$ (Tab. III), seis localidades (Antonina, São José dos Pinhais, Colombo, Ponta Grossa, Guarapuava, Fênix) apresentaram valores inferiores a 1,00, com dominância de fitófagos, portanto.

Em Telêmaco Borba houve uma predominância de não-fitófagos sobre fitófagos, com um valor de 1,512. Uma das razões da alta predominância de não-fitófagos, comparando-se aos dados das demais localidades, foi a presença do mais alto número de indivíduos de Scolytidae. Além da dificuldade em definir o 
hábito alimentar, que pode interferir no posicionamento desta família nas guildas, deve ser destacado que a área de coleta situa-se em uma reserva circundada por plantações de pinus (Pinus spp.), onde a infestação por indivíduos de Scolytidae é grande (PEDROSA-MACEDO 1984; SCHOENHERR 1985). Assim, o número proporcionalmente alto de indivíduos dessa família pode ser produto de uma migração intensa.

Em Jundiaí do Sul, a predominância de indivíduos não-fitófagos foi menor $(1,101)$, mas sobrepujando aos fitófagos, sendo o único local onde a família dominante tem hábito não-fitófago. Colombo foi o local em que se registrou a maior dominância dos fitófagos $(0,201)$.

Elemento importante a ser considerado é a forte dominância de indivíduos fitófagos nas localidades em que se registraram os menores índices de uniformidade (Colombo, Ponta Grossa, São José dos Pinhais e Antonina). Naquelas em que os índices de uniformidade foram mais altos houve um maior número de indivíduos não-fitófagos entre os $60 \%$ de indivíduos capturados (Telêmaco Borba e Jundiaí do Sul). A única localidade que não acompanhou esta tendência foi Guarapuava, que estando incluída entre as localidades de maior uniformidade apresentou a relação $\mathrm{NF} / \mathrm{F}$ superior apenas à de Colombo.

MORRIS (1980), em estudos de sucessão de vegetação a partir de pastagens, observou um mudança na dominância de besouros, terminando com a dominância de decompositores e fungívoros; e HUTCHESON (1990) reconheceu a existência de padrões semelhantes, com a dominância de herbívoros nas áreas em processo de regeneração e a dominância de elementos da guilda dos detritívoros em florestas maduras, que não foram perturbadas. Estes fenômenos foram observados também no presente estudo, incluindo apenas $60 \%$ do total de indivíduos capturados. Em áreas mais degradadas ou em ínício de regeneração, observou-se forte predominância de fitófagos; e em áreas menos perturbadas, ou em fase mais adiantada da sucessão vegetal, houve pouca ou nenhuma dominância dos fitófagos, como Jundiaí do Sul e Fênix.

Mesmo considerando-se Scolytidae como grupo fitófago, a relação entre fitófagos e não-fitófagos em Telêmaco Borba ainda assim indicaria equilíbrio entre as guildas, que é um dado interessante a considerar pois, apesar de HATSCHBACH (in MARINONI \& DUTRA 1993) ter indicado uma maior dificuldade para a recuperação da vegetação daquela área pela penetração intensa de taquara (Merostachis multiramea), a grande presença de indivíduos não-fitófagos indicaria uma fase mais avançada de regeneração da vegetação, se comparada à maioria das demais áreas estudadas.

BLENDEN et al., segundo HUTCHESON 1990, encontraram uma diminuição da biomassa de insetos (usando armadilhas malaise e rede de varredura) com o desenvolvimento do processo de sucessão vegetal. Apesar de não ter sido feito cálculo da biomassa, mas apenas analisado o número de indivíduos capturados, e ainda o fato do presente estudo não tratar da sucessão vegetal num mesmo local, é possível admitir que os dados deste trabalho não corroboram aquela avaliação. Nas localidades de Jundiaí do Sul e Fênix, onde há indicações de estarem em processo mais avançado de regeneração, o número de indivíduos capturados é muito díspar:

Revta bras. Zool. 14 (3): 751 - 770, 1997 
6152/1873. Este último valor, de Fênix, muito próximo ao de Antonina (1723), onde a grande dominância de fitófagos seria um indicativo de menor regeneração.

Observa-se, com mais este estudo, que a estrutura da vegetação tem influência, não só na diversidade de insetos ao definir o número de sua variedade (BRowN \& SOUTHWOOD 1983; WeBB et al. 1984), como possivelmente tem influência na composição taxonômica desta variedade.

\section{Diversidade BetA}

A comparação entre as localidades foi considerada de duas maneiras, utilizando os valores de captura média:

1) de indivíduos de cada um dos táxons, procurando identificar as localidades mais semelhantes com base nas relações entre indivíduos de uma mesma família;

2) de indivíduos ordenados por nivel de dominância de família em cada local; ou seja, comparando valores de mesmo nível de dominância nos diferentes locais, independente de táxon.

Em ambos os casos foi utilizado: o índice de Bray-Curtis, a partir de matriz de dados com os vetores (colunas) escalonados pela amplitude de variação (= "range"); o método de agrupamento por UPGMA. Apesar de estudos preliminares, utilizando Coeficiente de Correlação Linear, terem indicado agrupamentos de consenso absoluto, a partir de matrizes de dados com dados percentuais ou não, $\mathrm{e}$ escalonados ou não, optamos pelo uso do índice de Bray-Curtis. Esta preferência decorreu da semelhança dos resultados gerados pelos dois índices e pela possibilidade de aplicação dos valores deste último na Análise por Coordenadas Principais e na obtenção da Árvore de Conexão Mínima, também utilizadas neste estudo.

O escalonamento dos valores de captura dentro de uma mesma localidade visou: a) manter as relações entre as diferentes famílias num mesmo local; b) retirar a expressão do valor absoluto de captura $(\mathrm{N})$, já que o tamanho da amostra tem um efeito excessivo no índice de Bray-Curtis (WOLDA 1981).

Análise de Agrupamento (Árvore I, Fig. 1, Coeficiente de Correlação Cofenética $=0,757$ ) e Análise por Coordenadas Principais mais Árvore de Conexão Mínima (Fig. 2) da composição da fauna de Coleoptera, nível de família, a partir de dados de captura média de indivíduos de mesmo táxon nas oito localidades

A Árvore I mostra a formação de dois subconjuntos: a) um, formado pelo núcleo Antonina-Ponta Grossa, mais São José dos Pinhais, ao qual se une o núcleo Colombo-Guarapuavava; b) o outro, tendo um núcleo Jundiaí do Sul-Telêmaco Borba, ao qual se une Fênix.

\section{Discussão}

Desta análise depreende-se que houve uma maior semelhança, quanto às características taxonômicas, entre as localidades de Antonina, Ponta Grossa e São José dos Pinhais, mais o núcleo Colombo-Guarapuava, em oposição às tres localidades restantes. 


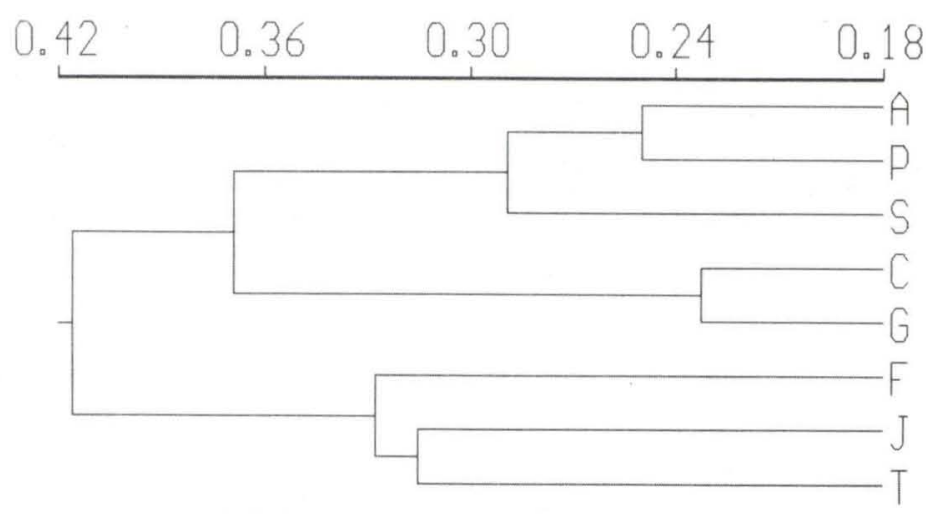

Fig. 1. Análise de Agrupamento. Árvore I. Locais de coleta $x$ valores de captura média de exemplares de familias de Coleoptera em cada local. (A) Antonina, (C) Colombo, (F) Fênix, (G) Guarapuava, (J) Jundiaí do Sul, (P) Ponta Grossa, (S) São José dos Pinhais, (T) Telêmaco Borba.

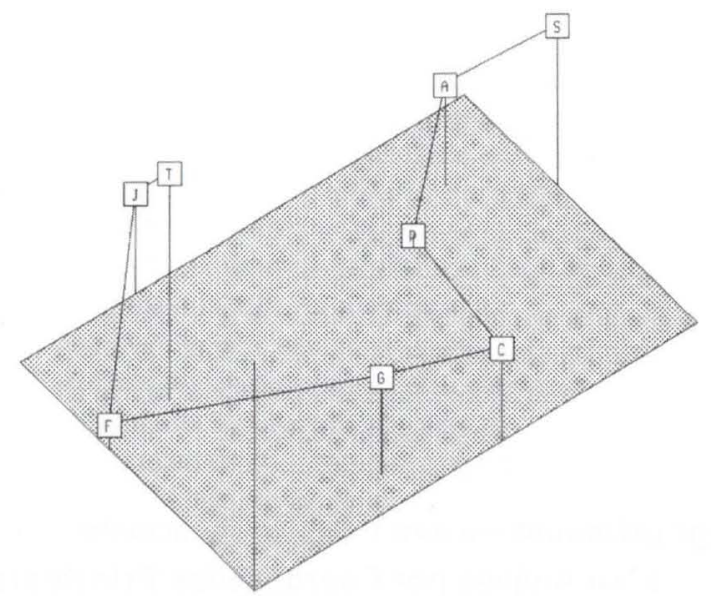

Fig. 2. Análise por Coordenadas Principais e ligação entre as localidades definidas pelos valores da Árvore de Conexão Mínima. Locais de coleta $x$ valores de captura média de exemplares de famílias de Coleoptera em cada local. Porcentagem do traço: primeiro eixo = 45,8; segundo eixo $=18,7$; terceiro eixo $=13,3$. (A) Antonina, $(C)$ Colombo, $(F)$ Fênix, $(G)$ Guarapuava, (J) Jundiai do Sul, (P) Ponta Grossa, (S) São José dos Pinhais, ( $T$ ) Telêmaco Borba.

Apesar da disparidade entre os valores absolutos de captura entre Ponta Grossa e as demais localidades do subconjunto (Tabs I e II), fica evidenciado que os diversos táxons apresentam-se com valores proporcionais semelhantes. Este mesmo relacionamento foi constatado entre Fênix, Jundiai do Sul e Telêmaco Borba. Este resultado pode indicar uma semelhança de estrutura vegetal nestas localidades, viabilizando a existência de indivíduos de espécies iguais ou diferentes de uma mesma família, que são dependentes das mesmas condições tróficas. 
Das análises, possiveis de estabelecer relações entre as localidades, como indicadas pela Árvore I (composição da fauna) e os valores de captura de exemplares das famílias com base no hábito alimentar (Tab. III), destaca-se que em Antonina, São José e Ponta Grossa, onde houve a predominância de Chrysomelidae, grupo eminentemente filófago, foi menor a captura de Curculionidae (com espécies espermófagas a xilófagas) e Cerambycidae (espécies xilófagas). O inverso ocorreu em Telêmaco Borba, Fênix e Guarapuava, onde houve menor captura de Chrysomelidae e maior captura de Curculionidae e Cerambycidae. Estes dados podem corroborar as indicações das condições ambientais já presumidas com as análises das relações entre familias fitófagas e não-fitófagas, observadas neste trabalho e por HUTCHESON (1990). Nos locais onde houve um número proporcionalmente maior dos indivíduos das famílias com hábitos alimentares ligados a plantas florestais, houve um número proporcionalmente menor de filófagos. Nestes locais houve uma maior uniformidade (Tab. II), mesmo a família dominante sendo de hábitos fitófagos.

Dois locais fogem das condições acima, Colombo e Jundiaí do Sul. Em Jundiaí do Sul, a maior uniformidade entre os valores de captura de indivíduos das diferentes famílias, tendo uma família não-fitófaga (Staphylinidae) como dominante, não produziu o mesmo quadro de relações entre Chrysomelidae, Curculionidae e Cerambycidae, se considerados apenas os valores individuais. Porém, a somatória dos valores de captura média de Curculionidae e Cerambycidae é maior que o valor de captura média de Chrysomelidae, repetindo os casos de Telêmaco Borba, Fênix e Guarapuava. A situação de Colombo é diferente. Este local, com baixo índice de uniformidade, tem Curculionidae como familia dominante. Neste caso somente uma análise dos hábitos alimentares a nível de subfamília ou grupos inferiores, talvez pudesse explicar esta relação discordante.

A posição do núcleo Colombo-Guarapuava é intermediária entre o subconjunto Antonina-Ponta Grossa-São José e o subconjunto Fênix-Jundiaí do Sul-Telêmaco Borba, como indica a figura 2 (análise por coordenadas principais e árvore de conexão mínima). Esta situação é coincidente com as avaliações relativas a nível trófico. Nestes locais os valores de NF/F foram baixos e houve dominância de Curculionidae-Cerambycidae. Colombo ficou mais próxima das localidades de menor uniformidade e Guarapuava das de maior uniformidade.

\section{Análise de Agrupamento (Árvore II, Fig. 3, Coeficiente de Correlação} Cofenética $=0,844)$ e Análise por Coordenadas Principais mais Árvore de Conexão Mínima (Fig. 4) da estrutura de comunidade a partir de dados de captura média de indivíduos das famílias de Coleoptera, ordenados por nível de dominância em cada local, independente de táxon

A Árvore II mostra dois subconjuntos. Um formado a partir do núcleo Antonina e São José, ao qual se unem sucessivamente Colombo e Ponta Grossa. O outro subconjunto, constituído por dois núcleos: Guarapuava-Fênix unido ao núcleo Jundiai do Sul-Telêmaco Borba. Pela figura 4, vê-se que a relação entre os subconjuntos se estabelece pelas localidades de Guarapuava e Antonina. 


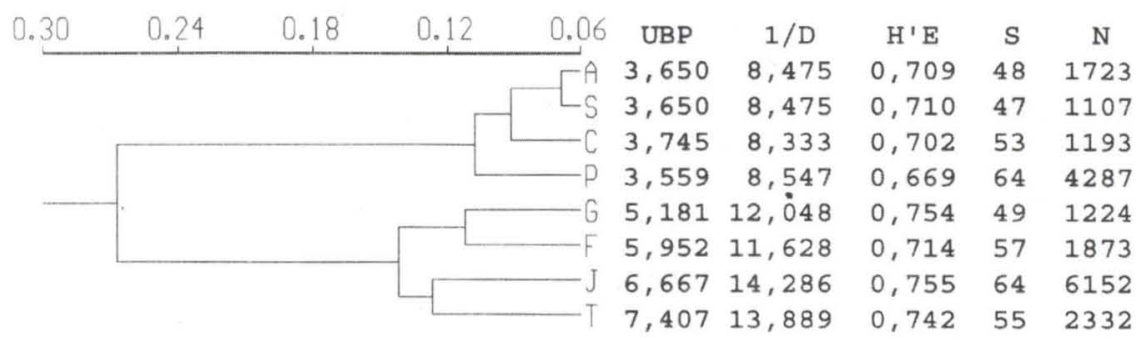

Fig. 3. Análise de Agrupamento comparada com diferentes indices de dominância/uniformidade. Árvore II. Locais de coleta $x$ vetores formados por valores decrescentes do número de exemplares por familia de Coleoptera. Colunas à direita correspondem à forma inversa do indice de dominância de Berger \& Parker (UBP); à forma inversa do índice de dominância de Simpson (1/D); ao indice de uniformidade de Shannon (H'E); e ao número de famílias (S) e de exemplares (N). (A) Antonina, (C) Colombo, (F) Fênix, (G) Guarapuava, (J) Jundiai do Sul, (P) Ponta Grossa, (S) São José dos Pinhais, (T) Telêmaco Borba.

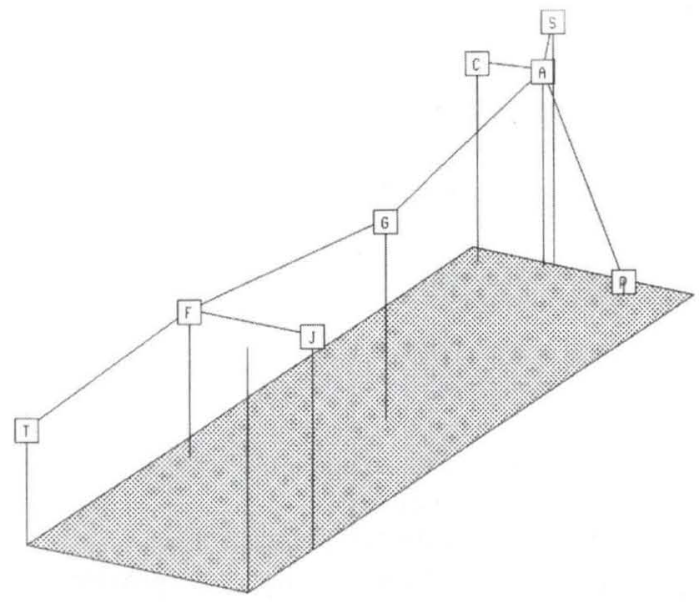

Fig. 4. Análise por Coordenadas Principais e ligação entre as localidades definidas pelos valores da Árvore de Conexão Mínima. Locais de coleta $x$ vetores formados por valores decrescentes do número de exemplares por familia de Coleoptera. Porcentagem do traço: primeiro eixo $=85,3$; segundo eixo $=4,6$; terceiro eixo $=4,00$. (A) Antonina, (C) Colombo, $(F)$ Fênix, (G) Guarapuava, (J) Jundiai do Sul, (P) Ponta Grossa, (S) São José dos Pinhais, (T) Telêmaco Borba.

As ligações entre as localidades confirmam as análises feitas através dos índices de uniformidade/dominância (Tab. II), com as localidades de Antonina, São José, Colombo e Ponta Grossa apresentando valores mais baixos de uniformidade e Telêmaco Borba, Jundiaí do Sul, Fênix e Guarapuava com valores mais altos.

Na comparação com os dados de niveis tróficos (Tabs III e IV), a localidade de Guarapuava mostra semelhança com as localidades de maior uniformidade, onde houve dominância de Curculionidae-Cerambycidae sobre Chrysomelidae. 
Pela figura 4, os dois subconjuntos unem-se através de Guarapuava e Antonina. A matriz de similaridade mostra que Guarapuava está a distâncias quase iguais de Antonina, São José dos Pinhais e Colombo, não havendo elementos que se possam destacar para explicar esta ligação, a não ser aquela que nos indica a metodologia, maior semelhança global.

Tabela IV. Valores percentuais de captura média de individuos de cada uma das familias de Coleoptera, arroladas na tabela III, em cada um dos locais de coleta. (AN) Antonina, (CO) Colombo, (FE) Fênix, (GU) Guarapuava, (JS) Jundiai do Sul, (PG) Ponta Grossa, (SJ) São José dos Pinhais, (TB) Telêmaco Borba.

\begin{tabular}{lrrrrrrrr}
\hline \multicolumn{1}{c}{ Familias } & AN & SJ & CO & PG & GU & FE & JS & TB \\
\hline Chrysomelidae & 27,4 & 27,4 & 17,7 & 28,1 & 11,7 & 8,1 & 13,0 & 10,4 \\
Curculionidae & 10,2 & 10,8 & 26,7 & 9,9 & 19,3 & 14,1 & 9,6 & 13,5 \\
Cerambycidae & 3,7 & 1,8 & 5,5 & 5,9 & 8,8 & 16,8 & 6,0 & 3,3 \\
& & & & & & & & \\
Staphylinidae & 13,3 & 13,1 & 5,4 & 8,1 & 7,5 & 9,4 & 15,0 & 9,9 \\
Mordellidae & 7,7 & 2,3 & 6,5 & 8,9 & 6,1 & 10,3 & 4,4 & 10,5 \\
Elateridae & 1,4 & 2,3 & 4,4 & 7,9 & 4,6 & 8,5 & 9,2 & 9,3 \\
Ptilodactylidae & 1,3 & 6,2 & 3,2 & 1,0 & 7,8 & 0,5 & 1,0 & 2,7 \\
Scolytidae & 4,2 & 2,2 & 1,4 & 0,6 & 3,1 & 0,6 & 1,4 & 6,2 \\
Cucujidae & 0,1 & 0,5 & 1,3 & 0,3 & 0,8 & 3,3 & 3,9 & 0,2 \\
Cleridae & 4,7 & 0,8 & 0,9 & 2,9 & 2,0 & 1,8 & 1,1 & 1,9 \\
Nitidulidae & 1,6 & 0,7 & 3,9 & 3,3 & 3,3 & 2,3 & 1,7 & 4,5 \\
Cantharidae & 0,4 & 6,1 & 1,3 & 2,6 & 0,3 & 0,0 & 0,9 & 0,9 \\
\hline
\end{tabular}

\section{CONSIDERAÇÕES FINAIS}

Os valores díspares que os diferentes indices de diversidade apresentam, ponderando de várias formas os valores de $\mathrm{S}$ (número de espécies) e de $\mathrm{N}$ (número de indivíduos), tornam os seus usos mais difíceis para uma interpretação biológica, que o simples uso de $\mathrm{S}$ e $\mathrm{N}$, individualmente.

Desta forma, os valores de $\mathrm{S}$, apontam para uma maior variedade de espécies em Jundiaí do Sul e Ponta Grossa. Nestes mesmos locais observam-se também os maiores valores de $\mathrm{N}$, indicando que as disponibilidades de nichos são as maiores dentre todos os oito locais. A simples interpretação destes dados indicam estes locais, juntamente com Fênix e Telêmaco Borba, como os que detêm as melhores condições de diversidade, e São José dos Pinhais e Antonina, as piores.

Quanto à interpretação das condições de uniformidade, ainda mostra ser mais adequada a utilização dos índices de dominância/uniformidade (os de Berger \& Parker, e de Simpson, principalmente). Apesar destes índices apresentarem valores que não têm um significado maior quando lidos individualmente, são de valor nos estudos comparados. Assim, os valores destes índices indicam Jundiaí do Sul e Telêmaco Borba como sendo os locais onde se observou uma maior uniformidade entre os números de indivíduos das várias famílias; e Ponta Grossa, Colombo, Antonina e São José dos Pinhais onde houve dominância acentuada de algumas familias. 
HATSCHBACH (in MARINONI \& DUTRA 1993), destacou que todas as oito localidades pesquisadas tinham sido alteradas pelo homem, em maior ou menor grau, quer pela extração de madeira nobres, quer de madeira de menor valor para lenha; os níveis destas alterações não sendo possível precisar, mas admitindo que havia maiores possibilidades de recuperação em uns locais que em outros.

Comparando-se estas informações com os resultados obtidos pela análise das famílias de Coleoptera, apoiadas na relações entre fitófagos e não-fitófagos, e na hipótese já levantada por MORRIS (1980) e HUTCHESON (1990) que indica uma maior presença da guilda dos fitófagos em áreas mais degradadas ou em início de sucessão vegetal, com o progressivo aumento do número de indivíduos até a dominância da guilda dos detritívoros e predadores, nas florestas maduras, ou naquelas que não foram perturbadas, pode-se admitir que: a) Jundiaí do Sul é a área em melhores condições de recuperação vegetal, onde já se observa a dominância da guilda de mais alto nível trófico; b) Telêmaco Borba, apesar de ter problemas de regeneração, e mesmo considerando a presença, talvez espúria, de Scolytidae, apresentou dados que qualificam a área como em bom nível de recuperação florística; c) Fênix, com um total de famílias superior e um total de indivíduos inferior a Telêmaco Borba, e com valores de uniformidade e de relação trófica altos, apresenta indicações de estar em fase de regeneração adiantada, coincidindo com as observações de Hatschbach.

Para as demais localidades, as análises indicam uma fase bem mais atrasada no processo de regeneração do ambiente, cabendo destaque para: a) Ponta Grossa, que tem a maior variedade de famílias (junto com Jundiaí do Sul) e um grande número de nichos; b) Colombo e Guarapuava, que apresentam dominância de famílias fitófagas, mas que não são filófagas; c) Antonina, considerada por Hatschbach como possuidora de bom poder de recuperação vegetal, ainda se iguala às localidades de mais baixo nível de regeneração.

Com estes estudos acrescem-se mais elementos que vêm corroborar as possibilidades da utilização de Coleoptera como um possível indicador de condições ambientais, principalmente nas comparações entre áreas florestadas que não foram perturbadas e aquelas em diferentes níveis de sucessão vegetal.

AGRADECIMENTOS. Reiteramos os nossos agradecimentos a todos aqueles que já tiveram seus nomes citados em trabalhos anteriores sobre o PROFAUPAR, acrescemos os de J.H.Pedrosa-Macedo e G.H.Rosado-Neto, e estendemos os agradecimentos aos revisores anônimos por sugestões e correções apresentadas.

\section{REFERÊNCIAS BIBLIOGRÁFICAS}

BRAY, J.R. \& C.T. CURTIS. 1957. An ordination of the upland forest communities of southern Wisconsin. Ecol.Monogr. 27: 325-349.

BRown, V.K. \& T.R.E. SouTHwOOD. 1983. Trophic diversity, niche breadth and generation times of exopterygote insects in a secondary succession. Oecologica 56: $220-225$.

Crowson, R.A. 1967. The Natural Classification of the Families of Coleoptera. 
Hampton, Ed. Classey Ltd., 187p.

- 1981. The Biology of the Coleoptera. London, Academic Press Inc.Ltd., $801 \mathrm{p}$.

Costa, C.; S. Vanin \& S.A. Casari-Chen. 1988. Larvas de Coleoptera do

Brasil. São Paulo, Museu de Zoologia Universidade de São Paulo, 282p.

DUTRA, R.R.C. \& R.D. MiYAZAKI. 1994. Famílias de Coleoptera capturadas em

oito localidades do Estado do Paraná, Brasil. Arq. Biol. Tecn. 37 (4): 889-894.

HutCHESON, J. 1990. Characterization of terrestrial insect communities using quantified, Malaise-trapped Coleoptera. Ecol. Ent. 15: 143-151.

LAWrenCE, J.F. 1982. Coleoptera, p.482-553. In: S. PARKER (Ed.) Synopsis and

Classification of Living Organisms. New York, McGraw Hill, 1232p.

LAWRENCE, J.F. \& E.B. BRITTON. 1991. Coleoptera (Beetles), p.543-683. In: CSIRO

(Ed.). The Insects of Australia. Melbourne Univ. Press, Vol. 2, $2^{\text {nd }}$ ed.

LiMA, A.M. DA C. 1952. Insetos do Brasil 7 (Coleópteros). Rio de Janeiro, Esc.

Nac. Agronomia, 372p.

. 1953. Insetos do Brasil 8 (Coleópteros). Rio de Janeiro, Esc. Nac. Agronomia, 323p.

1955. Insetos do Brasil 9 (Coleópteros). Rio de Janeiro, Esc. Nac. Agronomia, 289p.

—. 1956. Insetos do Brasil 10 (Coleópteros). Rio de Janeiro, Esc. Nac. Agronomia, 373p.

LlOYD, M., R.F. INGER \& F.W. KING. 1968. On the diversity of reptile and amphibian species in a Bornean rain forest. Amer. Natur. 102: 497-515.

MaC ARThur, R.H. 1965. Patterns of species diversity. Biol. Rew. 40: 510-533.

Magurran, A.E. 1988. Ecological diversity and its measurement. Princeton,

New Jersey, Princeton University Press, 179p.

MARINONI, R.C. \& R.R.C. DUTRA. 1993. Levantamento da fauna entomológica no

Estado do Paraná. I. Introdução. Situação climática e florística dos oito pontos

de coleta. Dados faunísticos de agosto de 1986 a julho de 1987. Revta bras.

Zool. 8 (1-4): 31-73 [1991].

- 1996. Levantamento da fauna entomológica no Estado do Paraná. II.

Ctenuchidae (Lepidoptera). Revta bras. Zool. 13 (2): 435-461.

MoRrIS, M.G. 1980. Insects and the environment in the U.K. Atti XII Congress

Nazionale Italiano Entomologia, Roma, 1: 203-205.

Pedrosa-Macedo, J.H. 1984. Riscos da não utilização de resíduos florestais,

p.40-49. In: Sobre Sistemas de Exploração e Transporte Florestal. Curitiba,

Fund. Pesq. Florestais.

PeEt, R.K. 1974. The measurement of species diversity. Ann. Rev. Ecol. System.

5: 285-307.

PenNY, N.D. \& J.R. ARIAS. 1982. Insects of an Amazon Forest. New York,

Columbia University Press, 269p.

Pielou, E.C. 1975. Ecological diversity. New York, J. Wiley \& Sons, 165p.

Poole, R.W. 1974. An Introduction to Quantitative Ecology. New York, MacGraw, 532p.

RoHLF, F.J. 1994. NTSYS-pc. Numerical Taxonomy and Multivariate Analysis 
System (version 1.80). New York, Exeter Software, VII+187p.

SCHOENHERR, J. 1985. Contribuição à taxonomia e ecologia dos escolitídeos do Brasil, p.116-126. In: IUFRO Workshop on Protection of Forests in the Tropics. Curitiba, Universidade Federal do Paraná.

SNEATH, P.H.A. \& R.R. SoKaL. 1973. Numerical Taxonomy. San Francisco, W.H.

Freeman and Company, 573p.

TownEs, H. 1972. A light-weight Malaise trap. Ent.News 83:239-247.

WEBB, N.R.; R.T. CLARKE \& J.T. NICHOLS. 1984. Invertebrate density on fragmented Calluna-heathland: effects of surrounding vegetation. Jour. Biogeog. 11: 41-46.

WHITTAKER, R.H. 1972. Evolution and measurement of species diversity. Taxon 21: $213-251$.

Williamson, M. 1973. Species diversity in ecological communities, p.325-335. In: M.S. BARTLETT (Ed.). The Mathematical Theory of the Dynamics of Biological Populations. London, Academic.

WoldA, H. 1981. Similarity indices, samples size and diversity. Oecologia 50: 296-302.

Recebido em 25.VII.1996; aceito em 10.IX.1997. 